\title{
Special Issue: "Performance evaluation of communications in distributed systems and Web based service architectures"
}

\author{
Lynda Mokdad • Mirela Sechi Moretti Annoni Notare
}

Received: 9 March 2011 / Accepted: 17 March 2011 / Published online: 13 April 2011

(C) Springer Science+Business Media, LLC 2011

This special issue is devoted to performance evaluation of communications in distributed systems and Web based service architectures. Due to the rapid evolution of IP networks with different network access (Optical, Ethernet, 3G, LTE, WIMAX, WIFI,... ), computer Systems (PC, smart phones, Ipads) and Web based services architectures, performance evaluation becomes essential but still a complex issue in general. The complexity is due to the heterogeneity of those systems and the diversity of considered applications.

The goal of the performance evaluation is analyzing and dimensioning those architectures in order to provide the Quality of Service (QoS) for the considered services and to maximize the bandwidth utilization.

Indeed, several challenges remain to be resolved before these systems become a commodity. Ensure QoS for webbased systems as well as distributed and mobile systems and evaluating their communication performance is a real challenge to design them.

Quantitative analysis can be very difficult and may be intractable because of the state space explosion. This is why recently new methodologies or/and tools emerged for these kinds of complex systems, such as Stochastic Automata Networks, Stochastic bounds, PEPA, just to mention a few.

This special issue selected the best papers of the IEEE workshop PEDISWESEA that was held in Riccione, Italy in 2010 and co-located with IEEE ISCC. These papers cover recent studies on the performance evaluation of communications in distributed systems and Web based service archi-

Prof. L. Mokdad $(\varangle)$

University of Paris-Est, Créteil, France

e-mail: lynda.mokdad@univ-paris12.fr

Prof. M.S.M.A. Notare

Barddal University, Florianopolis, Brazil tectures. We hope you will find set of papers interesting as much as we have done.

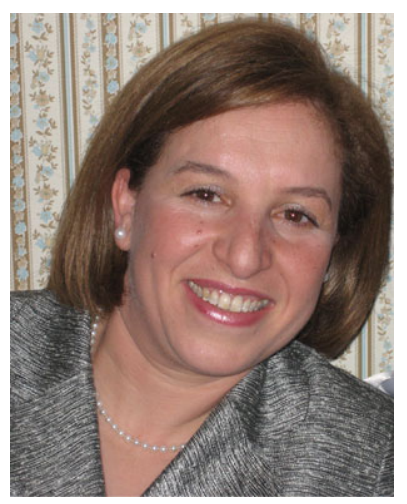

Prof. Lynda Mokdad received her $\mathrm{PhD}$ in computer science from the University of Versailles in 1997. She was associate professor at University of Paris-Dauphine from 1998 to 2009. She is professor at university of Paris-Est, Créteil since 2009. Her main research interests are about performance evaluation techniques and applications in wired, mobile and wireless networks and in software technologies as Web services.

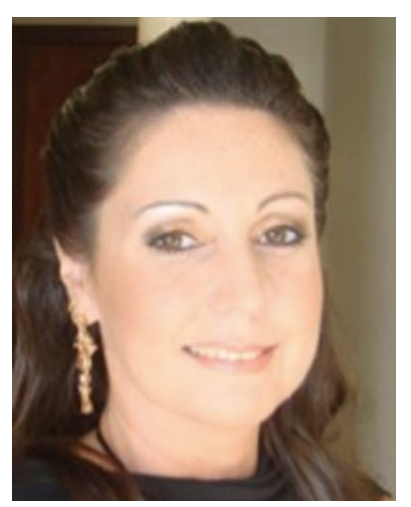

Prof. Mirela Sechi Moretti Annoni Notare is a Professor at Institute of Superior Education of Florianópolis (IESGF/UNIP) and Municipal University of Sao Jose, Brasil. She received her MSc and $\mathrm{PhD}$ degrees from the Federal University of Santa Catarina (UFSC) and a BSc degree from Passo Fundo University - all the three degrees in Computer Science. Her main research of interest focuses on the proposition of security management solutions for Wireless, Mobile, Sensor and AdHoc Networks. 